\title{
Study on Security Measures of the Physical Teaching
}

\author{
Pengfei Lin ${ }^{1}$ \\ ${ }^{1}$ Public Physical Education Department, Shandong Yingcai University, Jinan, Shandong, 250104
}

KEYWORDS: Physical Teaching; Security System; Teaching System

\begin{abstract}
From the late 1990s to recent years, China has continued research on sports safety. From the point of view of literature, the research in this area consists of two parts. Part of the study analyzes and discusses the factors that influence school sports injury, although various opinions are not very uniform, but that the basic school physical injury resulting from sports injury risk objectivity, bad or poor management of school facilities, teacher or student of human factors and said integrated due to several reasons. It is worth noting that the study of this point of view, although objectively describe the current school sports injury reasons, but most of them are subjective of rational analysis, the lack of actual data to prove it.
\end{abstract}

\section{Introduction}

PE from the point of view of structure, physical education into a preparatory part, and the end portion divided into three basic parts. Prepare safety measures and safety education section. Check carefully before class school PE teachers used equipment is intact, excluding sports venues security risks, right before physical education sports equipment placed on the presence of potentially hazardous equipment to send special care. When entering a regular part of the classroom, teachers should routinely review and timely to remind students not to bring any obstacles debris, asked whether the illness and physical discomfort of students. Lesson for the obvious danger of the project (such as shot put, etc.), teachers must emphasize safety at the beginning of class and ask students to strictly comply with the specific requirements relevant to enable students to understand the damage that may occur and to improve their safety awareness. Into the preparation stage activities, physical education teacher according to climatic conditions, physiological and psychological characteristics of students to arrange a suitable preparation activities. For example, the game content to be reasonable grounds, to avoid confusion in the form of the game, the teacher should be an accurate description of the rules, to be carried out effectively control the excitement of the students, in order to avoid injuries.

Basic safety measures and safety education part. PE teachers before class to do your homework, the sub-category, sub-level treatment, analysis and organization of exercise is good exercise intensity density of the lesson content, different students have different treatment. Not all students can adapt to the exercise intensity, but there can not meet the special needs of the students, if not arranged in advance, analyzed good exercise, may be part of the student body overload movement damage. Everything prevention first, so we have to expect to be able to explain the problems and urged before all movement. In the movement of the PE teachers to maintain a high concentration of the spirit, always pay attention to the students' motion, behavior. Enhance students' discipline, organization is the key to reducing the risk of emergence of a ring, for example, to avoid long-distance sports injuries due to physical discomfort occur suddenly, or confrontational competitions due to emotional excitement is too high, causing themselves or others damage and so on. 
Relaxing end portion. End part of a lesson is the most critical, first of all the various parts of the body to relax is to play a role in mitigation, relieve physical and mental tension, to avoid after-school physical injury occurred. Secondly, the problems in this lesson the teacher should summarize, let the students know what things should not be done in later life should be noted. Finally, under the teacher's guidance equipment recovery, collection class. The unauthorized handling, so organized and disciplined.

\section{The Reason of Accidents in PE Class}

First, as a physical education teacher, to establish safety awareness classes for teaching materials, prepare lesson: prepare students, prepare the organization, site preparation, equipment preparation, the safety factors in each teaching prone to be prepared to class and secondly, preparatory activities in the classroom is an important part cannot be ignored, seriously do general preparation activities and specialized preparations, make physical well into motion, muscles, joints, ligaments full activity; Third, to strengthen the management of classroom discipline and teaching organization, both to reflect the joy of movement, but also have good organizational order, prevent students in the practice of mutual interference, security problems; Fourth, reflect the leading role of teachers, doing exercises, explain when the demonstration action essentials should be clear, to make students understand plainly; arrangement of the driving range and sports equipment to be reasonable and check for good safety devices; when doing exercises note explaining the correct way of protection and help to avoid students practice when the fall, bumps.

PE mostly outdoors in classroom teaching, students often have a deep interest in the outdoor environment, classroom content, hyperactivity, restless is their nature, but poor control, safety awareness is weak, and therefore prone to security issues. Students in group exercises, easily excited when exercise equipment, if the boot is not good, it is prone to security issues. In addition, the student's strong competitiveness in mind, in practice catch, but also prone to security issues. There is the psychological quality of students is poor, poor frustration tolerance, difficulty, frustration is easy to produce fear, cowardice, timid to do the movements, which would prone to security problems in exercise equipment.

\section{Security Measures in Physical Education}

Physical education is a key part of school physical education, physical education teaching physical education is to achieve the most important form. Preparation part, the basic part and the end as part of three parts, physical education teacher physical education should be based on the content of these three parts is to take targeted safety measures and safety education. Teaching preparation section, $\mathrm{PE}$ teachers to carefully check before class equipment and facilities required for the class is intact, if the problem you need to eliminate safety hazards within the site, you will need sports equipment placed in the correct position to ensure students will not affect the activities of the presence of potentially hazardous equipment or send teachers to look after carefully supervised. When entering a regular part of the classroom, teachers should routinely check the students dress is appropriate to remind students not to impede movement hides with no debris, asking whether the sick and unwell students. Lesson for the obvious danger of the project, teachers must emphasize safety at the beginning of class and ask students to strictly comply with the specific requirements related to the existence of hidden dangers for students to action or practice to understand, to improve students' security awareness. Into the preparation stage activities, physical education teacher according to 
prevailing climatic conditions, physical and mental state of the student to arrange for appropriate preparation content.

Currently, both the educational administration, school administration and parents emphasis on school sports education security issues are to be improved, but for students hurt security awareness education of the accident almost in a vacuum, the students' safety awareness is weak and lacks self-defense ability, lack of safety knowledge. It is also a major cause of school sports injuries continue to occur. Therefore, to improve school sports safety education is desperately needed, and we should be on sports injury prevention education Accident formal education planning.

First, the school freshmen conduct a comprehensive physical examination or require students at county level or above experience report issued by the hospital, while the school should also conduct a physical fitness test prior to enrollment, students of medical reports and fitness test report common carrier the student health records, doing so on the one hand to facilitate the school teachers to master the basic situation of students' physical and mental development, on the other hand, in favor of PE teachers' individualized 'for different physical condition of students to enhance physical fitness to develop targeted recommendations. In addition, the physical condition is not suitable for those students in sports activities, the school also should be reasonable arrangements for a planned system of teaching content, to avoid accidents in the sports teaching process. Secondly, the establishment of the responsibility to contact the school, the student's health is not an aspect of the school with parents, schools and parents should be the common concern.

For a long time, it has been a middle school sports teaching an interdisciplinary, because the college entrance examination in this course is not included progression grades, so most schools are not special attention to teaching, but with the high school students physical decline, appears in PE Teaching the injuries to more and more, thus gradually causing various concerns. Countries such as the "sunshine sports", and called on high school students one hour a day activity, this activity requires all levels of government attention, and actively carry out various schools in order to achieve the ultimate goal, rather than as a slogan to appeal. As the school's management, you should understand the importance of this matter, to enable students to learn and lessons in culture, fully enjoy the fun of sports. The physical education as a student a platform to learn and master motor skills, school leaders should change the concept of the past, let the healthy growth of students, teachers and students a safe space. Therefore, school leaders should be given more lenient school sports policy to increase funding to increase the number of equipment to meet the more students use in sports teaching process; improving the quality of the hardware facilities, quality equipment to avoid damage caused to the student body; plus Great efforts to support and provide teachers out study and research opportunities for teachers to expand horizons.

After all, limited school funding required to meet the needs of all aspects of the schools in the form of sponsorship and corporate sponsors to make up for lack of funding through alumni, I believe there are many successful companies are willing to participate in charity, is called from the people, with the the people, the long-term goal of education is that students are the future construction of the motherland, as long as the needs of students, as long as the school for students to really work, I believe that more people are concerned about the community.

\section{Conclusion}

Physical education teaching safety and security, is concerned about security, love life. Emphasis on safety education from the start of every PE teacher, small part of the small details of the start. Safety education and safety related to the healthy growth of the students, but also to the ability of teachers in a peaceful, stable environment in teaching. 


\section{Reference:}

[1] Kaiser, R. A. Liability and law in recreation, parks, and sports [M]. Englewood Cliffs, NJ: Prentice Hall, (1986).

[2] Clement, A. Law in sport and physical activity [M]. Indianapolis, IN: Benchmark Press, (1988).

[3] Clement, A. Law in sport and physical activity (2nd Edition) [M]. Tallahassee, FL: Sport and Law Press, (1998).

[4] Van der Smissen, B. Legal liability and risk management for public and private entities [M]. Cincinnati, OH: Anderson, (1990).

[5] Berlonghi, A. The special event risk management manual [M]. Dana Point, CA: Author, (1990). 